\title{
A escola como entreposto cultural: o cultural e o simbólico no desenvolvimento democrático da escola*
}

\author{
Leonor Lima Torres \\ Universidade do Minho, Portugal
}

\section{Resumo}

Sujeita a uma multiplicidade de condicionamentos externos de grau e natureza distintos, a escola pública nunca, como nos dias de hoje, se viu confrontada com tantas diversidades culturais, sociais, politicas e ideológicas, que tanto a desafiam à assunção de lógicas de reconfiguração e mudança, como igualmente a colocam numa permanente tensão face à necessidade de preservar a sua matriz identitária, historicamente sedimentada. E é justamente perante este dilema estabelecido entre os factores de ordem externa que quotidianamente invadem as escolas (administração central e periférica, comunidades locais, entre outros) e os factores de natureza interna à escola (sociabilidades, práticas de convívio, rituais, costumes, tradições) que se jogam novas possibilidades de repensar o desenvolvimento democrático das escolas. Neste artigo retomámos a ideia de escola como entreposto cultural (Torres, 2004) - um espaço de cruzamento de culturas, de metamorfoses quotidianas de poder e de conflito, de relações diferenciadas entre actores escolares e educativos -, com o propósito de clarificar a relevância das dimensões culturais e simbólicas da organização escolar no desenvolvimento de processos de inovação e mudança e na exploração de (possíveis) vínculos de assessoria educativa. A nossa reflexão não deixará, por isso, de interrogar criticamente as temporalidades e as lógicas de acção num suposto novo espaço escolar, questionando o papel que os consequentes inputs culturais e políticos assumem na construção da autonomia e da escola democrática.

\section{Palavras-chave}

Cultura escolar; Cultura organizacional escolar; Autonomia democrática da escola 


\section{Conhecendo "por dentro" o quotidiano da escola portuguesa}

De forma mais expressiva a partir da Revolução de Abril de 1974, a educação escolar tem constituído objecto de discussão e debate permanente, numa procura incessante das suas funções sociais mais relevantes, dos modelos de organização e gestão escolar mais eficazes, dos factores mais determinantes do insucesso e do abandono escolares, dos figurinos curriculares mais adequados às novas dinâmicas sociais, enfim, tentando encontrar as causas e as soluções que ponham termo à tão propalada "crise da escola". Efectivamente, as várias propostas de mudança que se foram desenhando no tempo tiveram o condão de esbarrar quase sempre com fenómenos de resistência mais ou menos activa desenvolvidos nos mais diversos contextos escolares. Refém de um modelo de administração excessivamente centralizado, a escola pública portuguesa tem dado sinais evidentes, ao longo das várias temporalidades históricas, de que os processos de mudança e desenvolvimento escolar obedecem mais a lógicas de apropriação e objectivação concretizadas no contexto local e sempre a partir das racionalidades que presidem às práticas sociais dos actores do que a movimentos lineares de reprodução normativa. E, neste sentido, o conhecimento das lógicas de funcionamento das escolas concretas, do modo como estas construíram e sedimentaram no tempo a sua identidade própria, da forma como diferentes factores interferiram e condicionaram a sua cultura organizacional, constitui um eixo estruturante de qualquer projecto de mudança, quer ele seja despoletado a partir da administração central quer seja da iniciativa da gestão periférica e local das escolas.

Apesar do desenvolvimento recente de vários trabalhos de investigação sobre a realidade escolar portuguesa, a verdade é que ainda não dispomos de um capital de conhecimentos científicos suficientemente amplo e diversificado que nos permita retirar conclusões sólidas e definitivas sobre os múltiplos significados das práticas e dinâmicas escolares. Mesmo assim, e porque consideramos a realidade escolar como socialmente construída no devir histórico e, portanto, em permanente estado de reconfiguração cultural, o espólio de estudos empíricos realizados nas escolas e sobre as escolas portuguesas (cf. Lima, 1996; Canário, 1996) abre imensas pistas para repensar criticamente outros modos de operacionalizar 0 seu 
desenvolvimento democrático. Neste artigo, pretendemos debater a relevância dos factores culturais e simbólicos no processo de desenvolvimento democrático das escolas, começando por realçar os lugares e os espaços mais significativos na construção da cultura organizacional. Enquanto agência de mediação de diferentes racionalidades culturais, a escola assemelha-se metaforicamente a um entreposto cultural, a um posto dinâmico entre culturas que se confrontam permanentemente no espaçotempo escolar. Será a partir desta imagem de escola como entreposto cultural que procuraremos, na segunda parte do trabalho, explicitar as potencialidades dos processos de assessoria em educação.

A problematização das funções da assessoria educativa, no quadro mais específico de construção de uma escola pública alicerçada nos valores democráticos e participativos, assentará na discussão de duas concepções de assessoria: a assessoria de tipo gerencialista, enquadrada no movimento integrador da cultura, e a assessoria como processo político e participativo, referenciada ao movimento crítico da cultura. Em jeito de conclusão, arriscamos a enunciação crítica de dois cenários político-organizacionais para a escola portuguesa e as suas implicações na forma de se conceber as funções da assessoria em educação.

\section{Espaços e tempos na construção da cultura organizacional da escola}

Analisando a vastíssima literatura desenvolvida sobre a cultura organizacional, é possível identificar como uma das fragilidades teóricas mais expressivas, sobretudo ao nível dos trabalhos de natureza mais gestionária, a quase ausência de informação acerca dos processos de construção e reconstrução das dimensões culturais das organizações. Ao privilegiar-se, em primeiro plano, os processos de diagnóstico e de gestão das variáveis culturais e das suas relações com os resultados organizacionais, desfocou-se a atenção dos modos como se processa a construção e a consolidação das culturas, transferindo-se o enfoque para os processos de medição e de controlo dos indicadores culturais. Porém, não podemos verdadeiramente compreender a importância das especificidades culturais de uma dada organização sem primeiro identificarmos os tempos, os lugares e os espaços em que elas ocorrem. A relevância do simbólico e do cultural no contexto das 
organizações será tanto mais significativa quanto melhor conhecermos os factores que contribuíram para o seu desenvolvimento.

Face a este quadro de fundo, defendemos a adopção de uma focalização interpretativa e crítica da cultura organizacional que enfatize a sua natureza processual, dinâmica e dialéctica. Em termos fenomenológicos, o processo de construção da cultura organizacional constitui uma forma sustentada de hibridação, resultante de combinações, de interferências mútuas, de interfaces e interpenetrações entre um vasto conjunto de factores. Abordada como um processo dinâmico e de configuração variável, resultante de uma simbiose operada entre as circunstâncias externas (das locais às de âmbito global) e a forma como estas são construídas e reconstruídas nos contextos organizacionais concretos, a cultura organizacional assume, deste modo, uma natureza multiconfiguracional, podendo dar origem a distintas formas de manifestação cultural (integradora, diferenciadora, fragmentadora) (cf. Frost, Moore, Louis, Lundberg \& Martin, 1991; Martin, 1992, 2002). No seio das organizações é possível encontrar pelo menos três tipos de cultura, consoante o grau e a especificidade das suas manifestações: a cultura integradora, quando o grau de partilha e de identificação colectiva com os objectivos e valores da organização é elevado; a cultura diferenciadora, quando o grau de partilha cultural apenas se restringe ao grupo de referência, sendo provável a coexistência de distintas subculturas no mesmo contexto organizacional; por fim, a cultura fragmentadora, quando se constata o grau mínimo de partilha cultural, frequentemente adstrita à mera esfera individual. Nesta óptica, a questão nuclear não será a de saber se a organização tem ou não uma cultura, estritamente no sentido integrador do termo, mas, sobretudo, de conseguir identificar diferentes manifestações culturais num determinado contexto organizacional, compreender os múltiplos processos que presidem à sua construção e o seu real impacto ao nível do desenvolvimento estratégico, designadamente ao nível das (micro)políticas e das práticas quotidianamente postas em marcha nos mais diversos contextos de interacção social.

Erguido a partir de dois eixos principais, a grelha analítica representada na figura 1, procura ilustrar os diversos graus de implicação, articulação e de interdependência entre as respectivas categorias constituintes do eixo horizontal (fora/dentro) e do eixo vertical (estrutura/acção) no processo de construção da cultura organizacional em contextos escolares. Da intersecção entre os dois eixos resulta o recorte de quatro quadrantes, regulados por factores de incidência e expressão 
diferenciadas na construção cultural e simbólica: o quadrante 1, circunscrito ao binário estrutura/dentro, evidencia a centralidade da estrutura formal no processo de construção da cultura, induzindo uma relação de sobredeterminação da primeira sobre a segunda; o quadrante 2, localizado na intersecção entre a acção e o dentro, revela o protagonismo da agência humana no interior da organização na produção da sua cultura; o quadrante 3, situado na convergência entre a acção e o fora, aponta-nos para a influência exercida quer pelas trajectórias de socialização extra-escolar vivenciadas pelos actores escolares quer pelo genotipo cultural da comunidade/meio na construção da cultura organizacional da escola; por fim, o quadrante 4, restrito ao cruzamento dos campos estrutura/fora, sugere-nos a prevalência dos padrões estruturais, externamente contextualizados no nível político e na esfera profissional, no enquadramento das orientações normativas e culturais da organização escolar.

Figura 1 - Processo de construção da cultura organizacional da escola

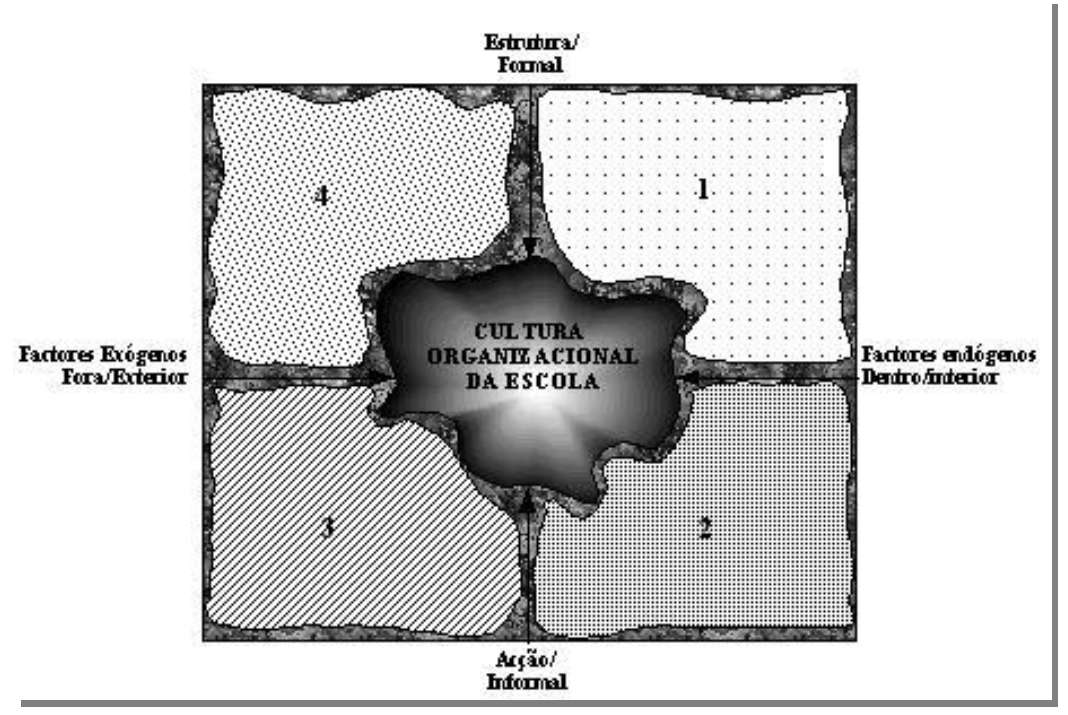

\section{A escola como entreposto cultural}

Sendo declarado o nosso interesse em compreender o funcionamento da organização escolar, mais concretamente sob orientação de um modelo 
analítico inspirado nas dimensões culturais e referenciado à realidade educativa portuguesa, assumimos à partida o pressuposto básico que a escola é em si mesma um fenómeno cultural, seja a um nível institucional mais lato, seja a um nível local e comunitário mais restrito. Ao assumirmos esta premissa, empregando um cunho cultural ao funcionamento do sistema educativo, não poderíamos deixar de considerar também as dinâmicas de interacção como produto cultural. Dificilmente encontraremos entre as mais relevantes instituições da modernidade um espaço tão intenso de produção cultural, de interacção social e de trocas simbólicas como a organização escolar, um espaço onde o trabalho humano recobre todo o seu sentido antropológico. O dinamismo institucional ilustrado pela rotatividade de um número considerável de professores e pela permanência limitada dos alunos nos anos específicos de escolaridade, transforma a escola num laboratório de sínteses culturais, um entreposto cultural como já tivemos oportunidade de a designar (Torres, 2004). Por mais que concebamos esta instituição como uma mera periferia de um centro de controlo escolar, que admitamos o seu carácter eminentemente reprodutor, ficariam, no entanto, por esclarecer os distintos modos de ser e de fazer, subjectivos e/ou colectivos, que se oferecem ao investigador no âmbito do seu labor sociológico.

A adopção de uma "perspectiva contextualizada" (Clegg, 1998) sobre a instituição escolar possibilita agarrar alguns momentos e espaços significativos que permitem elucidar os processos de construção e reconstrução cultural. $\mathrm{Na}$ nossa tese de doutoramento (Torres, 2004), propusemos a ideia de sedimentos culturais para dar conta de um património cultural e simbólico historicamente depositado na memória colectiva da instituição e que resultou do labor antropológico de apropriação das várias possibilidades da estrutura, nos vários espaços-tempo educativos da escola. Compreendeu-se que, mesmo em quadros de elevado constrangimento estrutural, a organização escolar conseguia gerar novas camadas sedimentares e realimentar o seu património cultural comum.

A imagem de escola como entreposto cultural serviu simultaneamente para complementar e pôr à prova a nossa proposta de análise, na medida em que as organizações escolares se tendem a caracterizar por elevados fluxos de informação e de conhecimento, de objectivos e finalidades diferenciados, de orientações e de regras de diversa índole, de racionalidades e de interesses diversos, de actores sociais com distintos papéis e funções, de interferências múltiplas, provenientes das diversas rotas do fora político e do 
multifacetado fora comunitário (cf. figura 2). Mas mais importante é notar o tempo relativamente longo proporcionado pela convivência e pela interacção dos actores no contexto escolar, com as implicações que estes processos acarretam na socialização e na construção e reconstrução de redes de significados individuais e colectivos, assim como na aprendizagem dos artefactos simbólicos que sedimentam a identidade organizacional.

Figura 1 - A escola como entreposto cultural

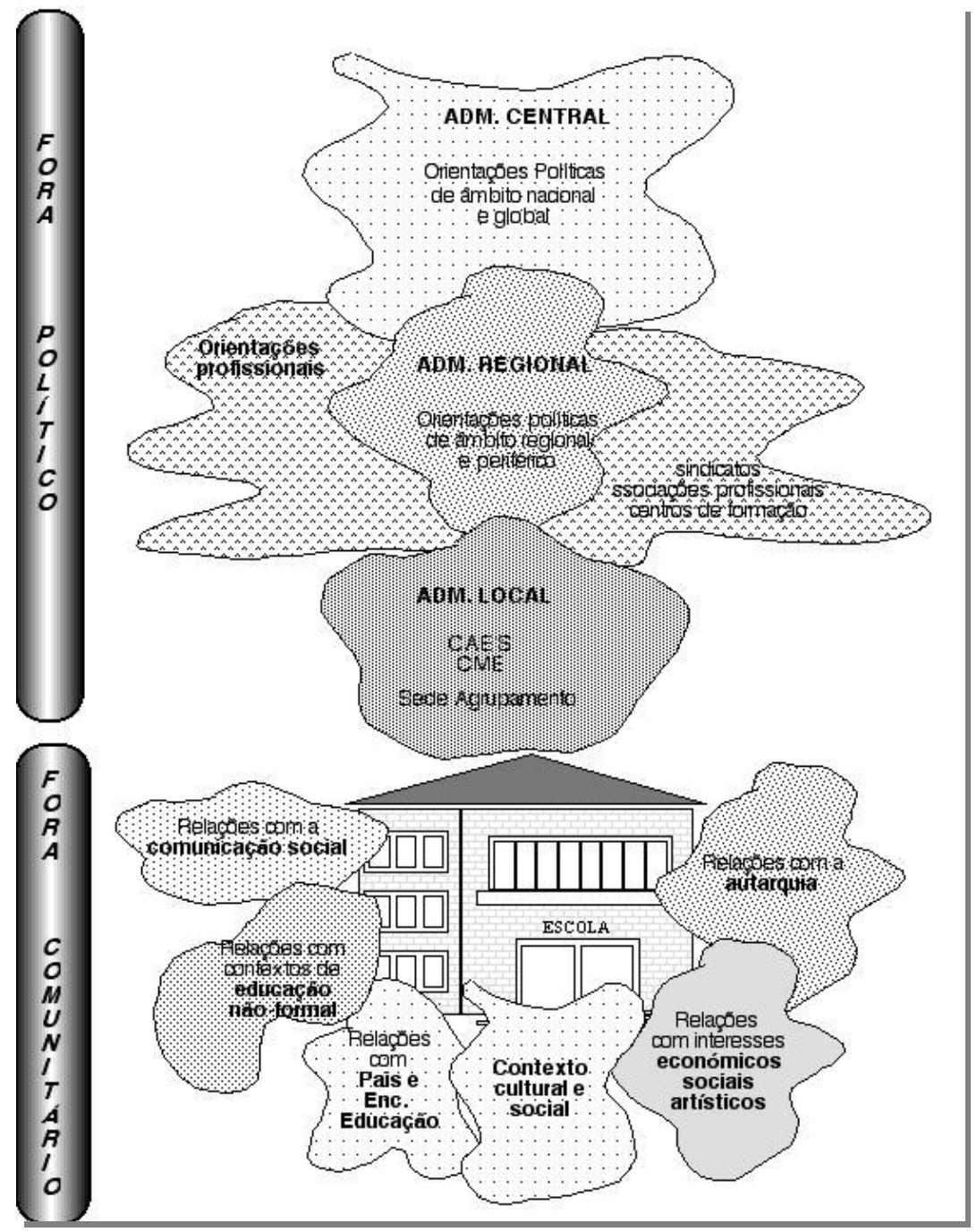


A figura 2 procura ilustrar a ideia de escola como entreposto cultural, posto entre lógicas culturais em trânsito entre os vários espaço-tempos do fora politico - situados e sobrepostos na complexa hierarquia da administração pública da educação (central, regional e local) - e do fora comunitário, perpassado por racionalidades, interesses e lógicas de poder distintas e, por vezes, contraditórias. Na figura 2, realçamos algumas instâncias que consideramos mais significativas do ponto de vista da natureza e da intensidade com que estabelecem relações (de poder, de colaboração e de negociação) com o espaço escolar: a autarquia, os pais e encarregados de educação, a comunicação social, os interesses económicos, sociais e políticos da região, os contextos de educação não-formal (Actividades de Tempos Livres, Centros de Estudo, Clubes Desportivos, Escolas de Música ...). Situada numa espécie de centro de confluência cultural, a organização escolar é, sem dúvida, um contexto propício e propiciador do desenvolvimento de complexas metamorfoses culturais construídas e sedimentadas no tempo e na memória colectiva da instituição.

A análise do impacto do exterior (foras) sobre os vários dentros escolares revela-nos distintas formas de reacção aos inputs culturais e normativos, em função das especificidades dos contextos formais de acção: Conselho Directivo/Executivo, Conselho Pedagógico, Assembleia e Direcção de Turma. Por exemplo, estamos em crer que o Conselho Executivo tende cada vez mais a exteriorizar-se politicamente, assumindo-se como uma delegação periférica para a execução das orientações centralmente definidas, muito embora tal não signifique uma absoluta permeabilidade às influências externas, nomeadamente por este órgão se encontrar num entreposto cultural para onde confluem distintas racionalidades, interesses, orientações e valores educativos. Admitir apenas a unidireccionalidade do centro, seria negar, por exemplo, a influência do fora comunitário, a centralidade das esferas simbólicas do dentro, o património histórico-cultural da instituição, enfim, sustentar o apogeu da era tecnológica, a formatação e a automação da estrutura sobre a acção humana. E, neste sentido, tal pressuporia o fim das instituições escolares locais e a educação tal como as concebemos.

O funcionamento de uma organização escolar pode assim ser dilucidado pela identificação das suas dimensões simbólico-culturais, nomeadamente pela sinalização das continuidades e das rupturas que as 
diversas conjunturas sociais, políticas, ideológicas e organizacionais tendem a produzir no quotidiano da escola. A compreensão das reformas educativas e das mudanças organizacionais não pode apenas privilegiar as determinações estruturais da agenda política, pois, como já tivemos oportunidade de comprovar, os diversos contextos escolares tendem a operar uma síntese interpretativa mediada pelos condicionalismos sociais e políticos de recepção e pela sua matriz consuetudinária.

\section{Interrogando as funções da assessoria educativa no quadro da construção da escola democrática}

Numa altura em que o advento de políticas neoliberais e neoconservadoras tende a instalar-se nas mais diversas esferas da vida social, o estudo de uma instituição escolar centrado no seu património simbólico e cultural pode constituir um desafio à interpretação da democracia como valor humano fundamental. Muito embora a democratização da escola portuguesa tenha deixado marcas indeléveis no seu quotidiano, a naturalização dessas conquistas, o alheamento participativo dos actores e o ensimesmamento político dos órgãos de governação da escola conferem à organização escolar um estatuto crítico no aprofundamento dos valores democráticos. Tendo a escola capacidades autoregenadoras e acreditando que qualquer processo de democratização política não pode dispensar a mobilização local dos actores, nem tão pouco as esferas estruturantes da vida social, a organização escolar terá que cinzelar de forma mais vincada no seu património simbólico e cultural os traços igualmente culturais da Democracia como desenvolvimento humano e educativo. E é neste quadro de fundo que as funções da assessoria em educação devem ser interrogadas e discutidas.

\subsection{Cultura como técnica de gestão e assessoria de tipo gerencialista}

Apesar de as investigações em torno da problemática da cultura organizacional em contexto escolar, no plano internacional, não constituírem, "a homogeneous body of literature and hence plotting its progress is a tenuous exercise" (Prosser, 1999: 1), é possível, mesmo assim, identificar a expansão e a popularidade de um movimento teórico que atravessa a grande maioria 
das pesquisas integradas nas quatro bases de dados por nós analisadas (UMI, ERIC, ABI-inform, ISI). A hegemonia da perspectiva integradora na análise da cultura organizacional em diversos contextos educativos, associada à adopção de metodologias de natureza quantitativa e estatística, inscreve-se num movimento mais amplo de afirmação das ideologias mais tecnicistas e gestionárias, voltadas para os valores da excelência, eficácia e produtividade.

A década de noventa, apogeu máximo deste movimento, ostentou alguns estudos de referência assinalável, invariavelmente centrados sobre o impacto da cultura da escola ao nível dos processos de mudança e inovação em várias e distintas esferas da educação. Assim, a cultura organizacional da escola é concebida, na maioria dos casos, como uma variável que a organização tem (variável dependente e interna) com fortes e inquestionáveis poderes de influência sobre o seu funcionamento.

Com o intuito de melhor compreendermos a natureza da relação cultura-mudança, construímos um quadro síntese (cf. quadro 1) com os resultados de uma análise de conteúdo efectuada aos resumos dos trabalhos inseridos na UMI e na ERIC, nomeadamente aqueles que, na nossa óptica, se enquadram no âmbito do movimento integrador da cultura organizacional em contexto escolar. A evidência empírica de que a cultura organizacional em contexto escolar se instituiu como um factor decisivo no alcance da eficácia, da performance e da excelência escolar, assim como na concretização efectiva das mudanças e das inovações, parece querer denunciar uma forte associação desta problemática com a ideologia gestionária subjacente ao "novo paradigma de gestão pública". Sobretudo quando parte de uma concepção dual e positivista da realidade (ora "reducionista" ora "expansionista") ${ }^{1}$, definida unicamente a partir de unidades mensuráveis, torna-se mais explícito a aproximação deste movimento integrador da cultura à doutrina ou paradigma da educação contábiR. 


\section{Quadro 1 - Efeitos da cultura organizacional sobre o funcionamento da escola (resultados da análise dos trabalhos que adoptaram a perspectiva integradora - UMI (1965-2002) e ERIC (1981-2002))}

\begin{tabular}{llll}
\hline Impacto da cultura organizacional sobre: & UMI & ERIC & Total \\
\hline Excelência, performance, eficácia, qualidade total & 14 & 12 & 26 \\
Mudanças, reestruturações, reformas, inovações & 10 & 10 & 20 \\
$\begin{array}{l}\text { Planeamento estratégico, processos de decisão, género na gestão, } \\
\text { processos de poder }\end{array}$ & 6 & 6 & 12 \\
Satisfação dos professores, comprometimento organizacional & 9 & 2 & 11 \\
Integração, socialização bem sucedida, ambiente, satisfação dos estudantes & 6 & 5 & 11 \\
Processos e perfis de liderança & 6 & 1 & 7 \\
Sucesso escolar, percursos escolares, produtividade escolar & 4 & 2 & 6 \\
Novas tecnologias & 4 & 1 & 5 \\
TOTAL & 59 & 39 & 98
\end{tabular}

É no quadro das ideologias gerencialistas ou das perspectivas neotaylorianas (Lima, 1994, 1997) — em clara expansão, no plano internacional, na administração do sector público e, em particular, no domínio educativo - fortemente arreigadas a teorias económicas, que a cultura organizacional em contexto escolar é reactualizada como tópico de investigação, agora subjugada à agenda tecnocrática, onde passa a ostentar o estatuto de "solução óptima" e de "one best way" para o alcance da eficácia, da performatividade e da competitividade. A literatura sobre a problemática da cultura organizacional em contexto escolar integrada no movimento integrador reflecte justamente aquelas lógicas, ao adoptar concepções instrumentais e funcionais da cultura como vias eficazes de acesso (ou como "meios óptimos") aos objectivos educativos.

A dupla pressão exercida sobre as organizações em geral e sobre as organizações educativas em particular, no sentido de simultaneamente conterem as despesas e de apresentarem resultados (de qualidade), exigiu a construção de indicadores mensuráveis, susceptíveis de engendrarem soluções de sucesso que garantissem a conformidade a um ideal imposto pela nova ideologia de gestão (Enteman, 1993) ou mesmo pelo paradigma de reinvenção do governo (Osborn \& Gaebler, 1992) - a procura da performance, a avaliação dos resultados, o controlo da qualidade, enfim, o reino dos três "E": Economia, Eficácia e Eficiência (Urio, 1998: 97). 
A cultura organizacional em contexto escolar é então concebida não só como uma variável de controlo (uma espécie de barómetro) na implementação das mudanças, mas igualmente como um instrumento de gestão e de assessoria eficaz para repor a ordem, a harmonia, a integração, o bom ambiente ao nível das relações sociais e profissionais nas instituições educativas. Este clima integrador e harmonioso torna-se efectivamente uma condição imprescindível para o bom desempenho e produtividade escolares, condição esta traduzida em alguns trabalhos pela relação estabelecida entre a cultura da escola e as taxas de sucesso escolar.

Mas de importância empírica mais significativa, registam-se os estudos sobre o impacto da cultura organizacional da escola ao nível dos processos de gestão e administração (cf. quadro 1), designadamente o planeamento estratégico, a feminização do poder, os perfis de liderança, entre outros factores, reforçando, uma vez mais, a ideia de aliança (estratégica) entre esta problemática e as ideologias políticas e gestionárias dominantes. A mensagem principal que atravessa grande parte dos estudos integradores da cultura reside na crença de que as culturas fortes (no sentido de coesas e integradoras) geram escolas mais eficazes, mais performantes e mais excelentes, enfim, com um potencial competitivo adequado às novas lógicas reguladoras e de sobrevivência, ditadas pelos mercados educacionais. E nesta sequência consensualiza-se a ideia de que o processo de liderança (cultural) nas escolas se torna vital para a promoção de culturas de excelência, como ficou bem expresso na conhecida obra de Cunningham \& Gresso (1993), sugestivamente intitulada Cultural Leadership: The Culture of Excellence in Education.

Face aos proclamados efeitos de desestruturação e fragmentação sociais e culturais inerentes ao processo de globalização económica e cultural, defende-se uma inflexão dos padrões culturais dominantes, retomando-se a (velha) ideia de que as organizações, enquanto células vitais de vida social, poderiam criar mecanismos compensatórios, gerando no seu interior culturas colaborativas e/ou colegiais susceptíveis de reporem a estabilidade e o equilíbrio social. Embora configurando um cenário assente em preocupações sociais de natureza aparentemente humanista e democrática, grande parte destes estudos denunciam, contudo, a subjugação (ou mesmo a instrumentalização técnica) daqueles valores às lógicas mais produtivistas ditadas no âmbito do mercado. 
Na esfera da educação, aquele cenário é tão evidente que convenceu autores de vários quadrantes teóricos a desenvolver estudos que, sob a égide de uma pretensa ampliação da democracia nas escolas, advogam a construção de culturas colaborativas e/ou colegiais, assentes numa participação mais efectiva, no trabalho de equipa, em lideranças fortes, como condição para se alcançar a excelência, a eficácia e a performance escolar ${ }^{3}$. $\mathrm{E}$, assim, consolida-se a crença de que as culturas se criam, se gerem, se formam, mas também se mudam e transformam ${ }^{4}$ ao sabor dos imperativos das ideologias da gestão (personificadas pelo líder e/ou pelos modernos processos de assessoria), independentemente de elas elegerem ou não, como prioridade educativa, o desenvolvimento dos valores da democracia e da participação.

\subsection{Culturas múltiplas e assessoria como processo político e participativo}

Celebrizando um registo mais crítico e problematizador na análise dos fenómenos culturais, o movimento crítico constitui já um suporte teórico e científico relativamente sustentado, sobretudo no contexto da educação escolar, quer ao nível das instâncias do ensino superior quer ao nível do ensino básico e secundário. As singularidades políticas e organizacionais da escola, ao alicerçarem-se sob diferentes "planos analíticos" 5 com impacto assinalável ao nível das práticas e interacções quotidianas, parecem exigir a convocação de modelos de análise alternativos, susceptíveis de melhor apreender o carácter holístico e multifactorial que subjaz ao "processo de construção e reconstrução da cultura da escola" (cf. Bates, 1987: 88-89; Sparkes \& Bloomer, 1993: 171).

Decorrente das especificidades do modelo organizativo da escola, o impacto das reformas educativas sobre os processos de mudança nas organizações escolares assume proporções mais expressivas ao visibilizar uma descontinuidade entre o contexto heterónimo de concepção de orientações/medidas (administração central) e o contexto localizado e periférico de adopção e implementação pelos actores (escolas). A constatação de uma certa desregulação e, por vezes mesmo, de uma ruptura profunda entre as esferas da concepção (objectivos) e os espaços concretos de implementação (resultados), fomentou a necessidade de se compreender, 
por um lado, as especificidades culturais dos contextos onde decorre a acção educativa e, por outro lado, a reacção destes a um conjunto de factores, como, por exemplo, um pacote de programas de acção externamente produzidos ${ }^{6}$. Esta dupla preocupação em olhar a cultura organizacional, simultaneamente como processo e produto, parece estar presente em grande parte das investigações enquadradas no movimento crítico.

Se bem que a resistência à dissociação das ideias cultura organizacional e desenvolvimento da escola continue presente nalguns trabalhos, privilegia-se, doravante, neste movimento, um enfoque multidisciplinar, susceptível de desocultar os factores intervenientes na construção da cultura organizacional da escola, podendo esta traduzir-se em distintas manifestações consoante o jogo de forças coexistentes em determinado contexto. Por isso, investe-se em abordagens mais holísticas, que extravasam os limites físicos da própria organização, ora enfatizando os processos de construção cultural de cima para baixo (top-down) ora questionando tal orientação, proclamando antes uma inflexão analítica, assente numa recentralização da escola como espaço investigativo, deslocando o enfoque de baixo para cima (down-top) ${ }^{7}$.

Ao procurar-se um quadro explicativo para os processos de construção e reconstrução da cultura organizacional da escola, sucederam-se investigações várias que procuravam evidenciar o carácter interactivo entre as diversas variáveis em jogo, umas mais internas à organização, outras de cariz mais exógeno à escola, explorando agora os contextos da acção concreta, os processos de negociação entre os actores, os palcos onde decorrem os conflitos, enfim, os domínios onde a construção do simbólico tem lugar.

$\mathrm{E}$, neste seguimento, os professores, os alunos e os pais, como protagonistas da acção educativa, tornaram-se nos actores mais investigados, enquanto potenciais representantes e competidores de distintas subculturas. Tomados como agentes pró-activos na construção e reconstrução da cultura organizacional da escola, as dinâmicas de interacção entre professores e alunos passam a ser exploradas de um duplo ponto de vista: como reflexos de uma estrutura escolar institucionalizada para a conformidade e convergência (normativa, ideológica, cultural), mas, em simultâneo, como denunciadoras de uma anti-estrutura de resistência, resultante de um complexo jogo de influências internas e externas à 
organização escolar. O desafio em questão será o de desvendar o complexo processo de produção e reprodução dos sistemas culturais nas e pelas escolas, partindo do pressuposto de que a instituição escolar poderá constituir apenas um espaço de mediação cultural entre a cultura societal e a cultura organizacional projectada. Ou, nas palavras de Pérez Gomez (1998: 12), a escola deveria ser entendida como um cruzamento de culturas, "que provocan tensiones, aperturas, restricciones y contrastes en la construcción de significados".

A natureza multidisciplinar deste movimento, assim como a sua associação a metodologias de investigação mais qualitativas, não só permitiu uma abordagem mais aprofundada e consolidada sobre a problemática da cultura em contexto escolar, como correlativamente desmistificou algumas apropriações ideológicas e políticas a que aquela tem sido sujeita. Ao denunciar-se a presença de diferenciadas manifestações culturais (cultura integradora, diferenciadora e/ou fragmentadora) num mesmo contexto escolar, resultante de um jogo dialéctico de forças internas e externas à escola, questiona-se como consequência a natureza positivista e estática dos pressupostos integradores da cultura, assim como a sua relação directa com a eficácia e a eficiência escolares.

É no quadro dos pressupostos desenvolvidos no seio deste movimento crítico que faz sentido, na nossa opinião, interrogar os sentidos e as funções da assessoria em educação. Independentemente dos significados atribuídos à expressão assessoria, que, como sabemos, recobre uma multiplicidade de sentidos, parece-nos mais pertinente explorar as suas diferentes formas de manifestação no contexto da realidade educativa portuguesa. Se é verdade que, no plano internacional, a tendência dominante revela a adopção de uma assessoria de tipo gerencialista e tecnocrático, fundamentalmente centrada na correcção e ajustamento das dimensões técnicas susceptíveis de fabricarem a excelência e a eficácia escolares, é preciso não ignorar a possibilidade de desenvolvimento de outras formas alternativas de assessoria, mais congruentes com a natureza e a especificidade da cultura organizacional da escola e ao serviço da missão democratizadora da instituição escolar.

De forma a melhor clarificar esta segunda acepção de assessoria, na nossa óptica, aquela que estaria mais congruente com a ideia de uma escola 
mais democrática e autónoma, apresentamos graficamente a sinalização de duas concepções de escola antagónicas do ponto de vista político, organizacional e cultural. A primeira, situada no lado esquerdo da figura 3 , pretende ilustrar uma imagem de escola relativamente cristalizada no imaginário colectivo, muito marcada pela ideia de reprodução burocrática do sistema central, um espaço que reflecte sobretudo uma cultura escolar institucionalizada, onde o centralismo e a uniformidade política, administrativa e pedagógica constituem o elemento mais marcante. Sobredeterminada exclusivamente pelos factores exógenos, esta imagem de escola articula-se com uma modalidade de assessoria de tipo externo e de cariz técnico e administrativo, centrada sobretudo no aprimoramento dos meios e das técnicas conducentes ao alcance dos resultados. Ressalta deste primeiro cenário uma assessoria centrada nos domínios mais instrumental e implementativo, aqueles que legitimam e reforçam os valores burocráticos do sistema.

\section{Figura 3 - Perspectivas de escola e funções da assessoria}

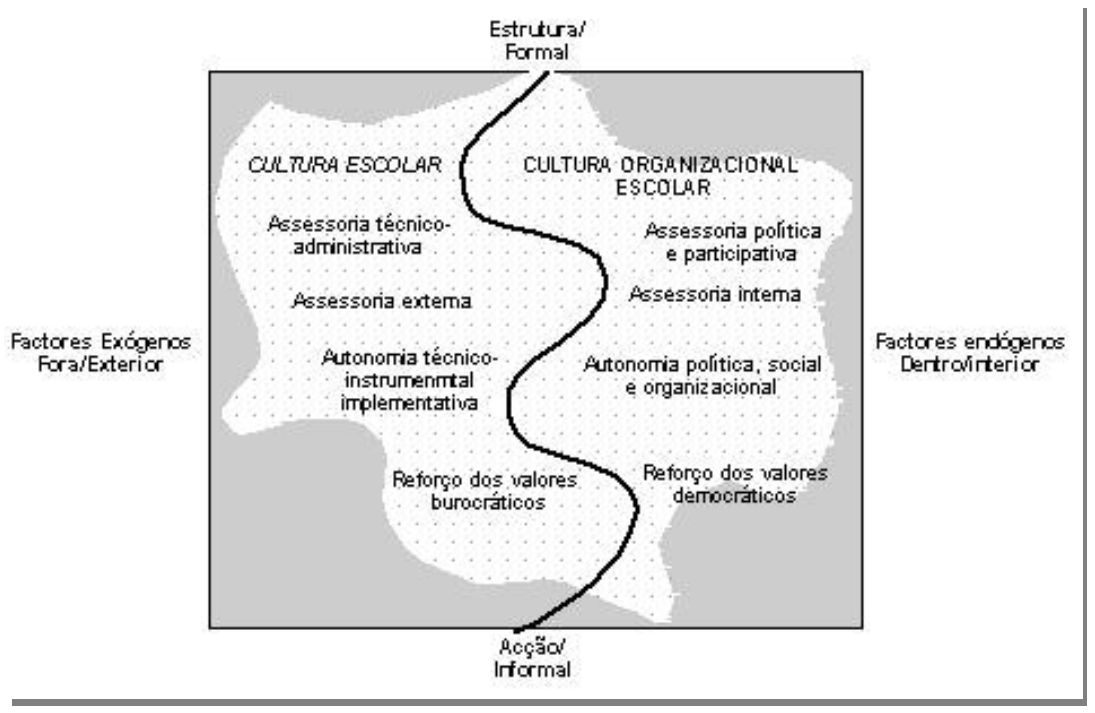


A segunda acepção, situada no lado oposto da figura 3, pretende ilustrar uma outra forma de perspectivar a escola, agora mais alicerçada nas especificidades reais do seu funcionamento, nas singularidades dos seus actores e nos espaços-tempo de construção simbólica e cultural. Detentora de uma cultura organizacional escolar, a instituição escola emerge neste cenário dotada de uma identidade historicamente sedimentada que integra no seu interior diversas formas de manifestação cultural. À luz desta imagem, mais focalizada nos mundos vividos (Boltanski \& Thévenot, 1991; Dérouet, 2000) dos actores escolares (tanto ao nível das dinâmicas como das regularidades de interacção), todas as escolas são diferentes do ponto de vista da sua matriz cultural e simbólica. Consequentemente, os quadros axiológiconormativos partilhados pelos actores de diferentes escolas apresentam, inevitavelmente, diferentes graus de intensidade quanto à interiorização e aprendizagem dos valores democráticos e participativos. Será neste quadro de fundo que contempla a coexistência, nas mais diversas instituições de ensino, de diferentes graus de desenvolvimento da cultura democrática, que faz sentido reposicionar a função da assessoria educativa.

Se a agenda política se centrasse, de facto, no reforço da autonomia democrática da escola portuguesa, o tipo de assessoria mais congruente com tal propósito seria a de uma assessoria interna à escola e de natureza éticopolítica, de forma a fomentar nos mais diversos tempos e espaços escolares uma cultura de participação assente expressivamente em valores democráticos, devolvendo à escola pública o sentido cívico e comunitário (Barroso, 1996, 1998). Tratar-se-ia, neste caso, de uma assessoria enquanto processo dinâmico a desenrolar-se na e pela acção quotidiana dos actores, mais centrada nos princípios orientadores da praxis educativa do que na mera operacionalização dos meios técnicos heteronomamente definidos. E, neste sentido, julgamos que a investigação científica (teórica e empírica) constitui e tem constituído, sem dúvida, uma dimensão estruturante do processo de assessoria em educação. Os resultados teóricos e empíricos das diversas pesquisas desenvolvidas no âmbito da educação representam na actualidade um espólio de conhecimento fundamental para o desenvolvimento estratégico das instituições educativas. Quer no domínio mais estritamente académico, onde se produzem dissertações e teses nas mais diversas áreas de especialização do campo educativo, quer ao nível de projectos orientados 
para a aç̧ão concreta, a organização escolar tem sido objecto de múltiplas abordagens teóricas e metodológicas, traduzidas na operacionalização de uma grande variedade de métodos e técnicas de pesquisa empírica. Os estudos de análise extensiva, menos frequentes no nosso país, assim como os trabalhos de enfoque intensivo, com grande relevância para os estudos de caso, constituem já um importante acervo de informação sobre os modos de funcionamento da organização escolar passível de ser mobilizado pelos diversos actores educativos (professores, gestores, pais, técnicos de educação, entre outros) no contexto da acção concreta. Neste sentido, o recurso ao conhecimento científico como estratégia de orientação e legitimação da praxis política enquadrar-se-ia do ponto da nossa matriz teórica num processo de assessoria ético-política. Estamos em crer que não é possível desenvolver démarches de assessoria com efeitos transformadores sem se conhecer profundamente os sedimentos culturais das realidades que se pretendem transformar.

\section{Notas}

* Este artigo constitui um aprofundamento de uma comunicação apresentada em Maio de 2006 no IV Simpósio em Organização e Gestão Escolar (Universidade de Aveiro) e posteriormente publicada com o título A Escola Como Entreposto Cultural: Espaços e Tempos na Reconfiguração da Cultura Organizacional da Escola no Livro de Actas organizado por J. A. Costa, A. Neto-Mendes e A. Ventura (2007). A Assessoria em Educação em Debate. Aveiro: Universidade de Aveiro, pp. 195-204.

1 Michel St-Germain, no artigo "Une conséquence de la nouvelle gestion publique: l'émergence d'une pensée comptable en éducation", parte da distinção entre uma concepção "reducionista" (que reduz a realidade a indicadores pré-estabelecidos) e uma concepção "expansionista" (que identifica novos indicadores para apreender a realidade na sua totalidade), para concluir que, ambas as leituras da realidade, embarcam em pressupostos positivistas e, portanto, muito próximos do pensamento contábil. Cf. St-Germain (2001: 2-3).

2 A análise dos efeitos deste paradigma no domínio da educação tem sido desenvolvida por alguns autores, entre os quais destacamos Self (1993), Fergusson (1994), St-Germain (2001). Entre nós, o destaque vai para os trabalhos desenvolvidos por Correia, Stoleroff \& Stoer (1993) e por Lima (1994; 1997). A propósito do paradigma da educação contábil, entre nós foi pioneiro o trabalho de Lima (1997).

3 Entre outros trabalhos referenciáveis nesta rubrica, salientamos as obras de Deal (1988), Cunningham \& Gresso (1993), Bolman \& Deal (1994), Thurler (1994), Hargreaves (1996), James (1999) e Sallán (2000). 
4 A ideia de que a cultura organizacional constitui um objecto manipulável e, em certo sentido, domesticável, apesar da controvérsia teórica a que tem sido sujeita, continua em franca expansão no domínio da educação. Veja-se a este propósito, a tese de doutoramento realizada por Biggerstaff (1990) - Creating, Managing, and Transforming Organizational Culture in the Community College: Perspectives of Reputationally Effective Presidents. The University of Texas at Austin. PhD, 363 págs. (UMI).

5 Referimo-nos, na esteira de Licínio Lima, ao "plano das orientações para a acção" e ao "plano da acção organizacional", regidos por distintas regras e lógicas organizacionais. Para uma análise mais aprofundada do modelo teórico construído por este autor, consultar Lima (1992).

6 É nesta linha de argumentação que podemos enquadrar o recente trabalho de Lúcia Teixeira (2001) intitulado A Cultura Organizacional e o Impacto das Propostas de Mudança em Escolas Estaduais de Minas Gerais, onde a autora questiona o impacto de propostas de mudança centralmente concebidas sobre o funcionamento de escolas com especificidades culturais e identitárias distintas. Igualmente elucidativo, Elmore (1987) reflecte a propósito das relações entre o plano da concepção da reforma educativa, externamente localizado, e o plano da "ordem normativa" (cultura de escola), organizacionalmente construído, procurando analisar e explicar as razões da resistência dos professores à reforma, por referência à especificidade da "cultura de autoridade" desenvolvida nas escolas.

7 No âmbito desta linha, sugerimos a consulta da dissertação de mestrado produzida no Canadá por Schill (1992) - Emergent Organizational Culture: The Study of a Developing School System. University of Calgary (Canadá). MA, 127 págs. (UMI), onde $o$ autor identifica os valores e as orientações que formam a base da cultura de uma escola, partindo do pressuposto de que tal cultura constitui o reflexo de factores externos (ora mais distantes ora mais localizados na comunidade) e de factores internos à escola. O autor conclui que a formação da cultura organizacional não constitui um processo de cima para baixo (top-down), antes traduzindo um percurso inverso, onde os actores se assumem como protagonistas na produção cultural.

\section{Referências}

ALVESSON, Mats (2002). Understanding Organizational Culture. London: Sage Publications.

BARROSO, João (1996). Para o Desenvolvimento de uma Cultura de Participação na Escola. Lisboa: Instituto de Inovação Educacional.

BARROSO, João (1998). Descentralização e autonomia: devolver o sentido cívico e comunitário à escola pública. Revista Colóquio/Educação e Sociedade, nำ 4 (nova série), pp. 32-58.

BATES, Richard J. (1987). Corporate culture, schooling, and educational administration. Educational Administration Quarterly, Vol. 23, ํㅡ 4, pp. 79-115. 
BOLMAN, Lee G. \& DEAL, Terrence E. (1994). Becoming a Teacher Leader. From Isolation to Collaboration. Thousand Oaks: Corwin Press, Inc.

BOLTANSKI, Luc \& THÉVENOT, Laurent (1991). De la Justification. Les Économies de la Grandeur. Paris: Gallimard.

CANÁRIO, Rui (1996). Os estudos sobre a escola: problemas e perspectivas. In J. Barroso (Org.), O Estudo da Escola. Porto: Porto Editora, pp. 121-149.

CLEGG, Stewart (1998). As Organizações Modernas. Oeiras: Celta Editora.

CORREIA, José A.; STOLEROFF, Alan D. \& STOER, Stephen (1993). A ideologia da modernização no sistema educativo em Portugal. Cadernos de Ciências Sociais, ํㅜ 12/13, pp. 25-51.

CUNNINGHAM, William G. \& GRESSO, Donn W. (1993). Cultural Leadership: The Culture of Excellence in Education. Boston: Allyn and Bacon.

DEAL, Terrence (1988). The symbolism of effective schools. In A. Westoby, Culture and Power in Educational Organizations. Milton Keynes: Open University Press, pp. 198-222.

DEROUET, Jean-Louis (2000). L'École dans Plusieurs Mondes. Bruxelles: De Boeck e Larcier.

ELMORE, Richard F. (1987). Reform and the culture of authority in schools. Educational Administration Quarterly, Vol. 23, no 4, pp. 60-78.

ENTEMAN, Willard E. (1993). Managerialism The Emergence of a New Ideology. Madison: The University of Wisconsin Press.

FERGUSSON, Ross (1994). Managerialism in education. In J. Clarke; A. Cochrane \& E. McLaughlin (Orgs.), Managing Social Policy. London: Sage Publications, pp. 93114.

FROST, Peter J.; MOORE, Larry F.; LOUIS, Meryl R.; LUNDBERG, Craig C. \& MARTIN, Joanne (Eds.) (1991). Reframing Organizational Culture. London: Sage Publications.

HARGREAVES, Andy (1996). Profesorado, Cultura Y Postmodernidade (Cambian los Tiempos, Cambia el profesorado). Madrid: Ediciones Morata, S. L.

JAMES, Chris (1999). Institutional transformation and educational management. In T. Bush; L. A. Bell; R. Bolam; R. Glatter \& P. M. Ribbins (Eds.), Educational Management. Redefining Theory, Policy and Practice. London: Paul Chapman Publishing Ltd., pp. 142-154.

LIMA, Licínio C. (1994). Modernização, racionalização e optimização: perspectivas neotaylorianas na organização e administração da educação. Cadernos de Ciências Sociais, no 14, pp. 119-139.

LIMA, Licínio C. (1996). Construindo um objecto: para uma análise crítica da investigação portuguesa sobre a escola. In J. Barroso (Org.), O Estudo da Escola. Porto: Porto Editora, pp. 17-39.

LIMA, Licínio C. (1997). O paradigma da educação contábil — políticas educativas e perspectivas gerencialistas no Ensino Superior em Portugal. Revista Brasileira de Educação, no 4, pp. 43-59. 
MARTIN, Joanne (1992). Cultures in Organizations. Three Perspectives. New York, Oxford: Oxford University Press.London: Sage Publications, pp. 58-76.

MARTIN, Joanne (2002). Organizational Culture. Mapping the Terrain. London: Sage Publications.

OSBORN, David \& GAEBLER, Ted (1992). Reinventing Governement: How the Entrepreneurial Spirit is Transformating the Public Sector. Reading MA: Addison-Wesley.

PÉREZ GÓMEZ, Ángel I. (1998). La Cultura Escolar en la Sociedad Neoliberal. Madrid: Ediciones Morata, S. L.

PROSSER, Jon (Ed.) (1999). School Culture. London: Sage Publications.

SALLÁN, Joaquín (2000). Cambio de cultura y organizaciones que aprenden. Educar, no 27, pp. 31-85.

SELF, Peter (1993). Government by the Market? The Politics of Public Choice. London: Macmillan.

SPARKES, Andrew C. \& BLOOMER, Martin (1993). Teaching cultures and school-Based management: towards a collaborative reconstruction. In J. Smyth (Ed.), $A$ Socially Critical View of the Self Management School. London: The Palmer Press, pp. 171-189.

ST-GERMAIN, Michel (2001). Une conséquence de la nouvelle gestion publique: l'émergence d'une pensée comptable en Éducation. Éducation et Francophonie, Vol. XXIX, no 2, pp. 1-23 [Disponível em www.acelf.ca/revue].

TEIXEIRA, Lúcia (2001). A cultura organizacional e o impacto das propostas de mudança em escolas estaduais de Minas Gerais. In L. F. Dourado \& V. H. Paro (Orgs.), Políticas Públicas e Educação Básica. São Paulo: Xamã.

THURLER, Monica Gather (1994). Relations profissionnelles et culture des établissements scolaires: au-delà du culte de líndividualisme?. Revue Française de Pédagogie, № 109, pp. 19-39.

TORRES, Leonor (1997). Cultura Organizacional Escolar: Representações dos Professores Numa Escola Portuguesa. Oeiras: Celta Editora.

TORRES, Leonor (2004). Cultura Organizacional em Contexto Educativo. Sedimentos Culturais e Processos de Construção do Simbólico Numa Escola Secundária. Braga: Centro de Investigação em Educação e Psicologia da Universidade do Minho.

URIO, Paolo (1998). La gestion publique au service du marche. In M. Huffy (Dir.), La Pensée Comptable. Paris: PUF, pp. 91-124. 


\section{SCHOOL AS A CULTURAL TRADEPOST: THE CULTURAL AND THE SYMBOLIC IN THE DEMOCRATIC DEVELOPMENT OF SCHOOL}

Abstract

Exposed to a wide range of external regulating factors of varying degree and nature, the public school has never been faced with so many cultural, social, political, and ideological diversities as it is today. These diversities not only challenge the school to adopt logics of change and reconfiguration, but also create a state of permanent tension with regard to the need to safeguard it's historically grounded identity matrix. And it is precisely within this dilemma created between factors which are external in nature and invade schools on a daily basis (central and peripheral administration, local communities, just to name a few) and factors which are internal in nature (sociabilities, socializing practices, rituals, customs, traditions) that lie new possibilities to rethink the democratic development of schools. In this article, we take up the idea of school as a cultural tradepost (Torres, 2004) - a place where cultures cross, of daily metamorphoses of power and of conflict, of differentiated relations between school and educational actors (players) - , with the purpose of making clearer the relevance of the cultural and symbolic dimensions of the school organization in the development of processes of innovation and change and in the exploration of (possible) educative assessorial bonds. Our reflections will not, therefore, turn away from the critical questioning of the temporalities and the logics of action in the proclaimed new school arena, examining the role that the consequential cultural and political inputs play in the creation of autonomy and the democratic school.

Keywords

School culture; School organizational culture; Democratic autonomy of the school 


\title{
L'ÉCOLE COMME ENTREPÔT CULTUREL: LE CULTUREL ET LE SYMBOLIC DANS LE DÉVELOPPEMENT DÉMOCRATIQUE DE L'ÉCOLE
}

\author{
Résumé
}

Sujet à une multiplicité de conditionnements externes de degré et nature distinct, l'école publique jamais comme de nos jours s'est vue confrontée à autant diversités culturelles, sociales, politiques et idéologiques, que de telle façon ils la défient à l'assomption des logiques de reconfiguration et de changement, comme également ils la placent dans une permanente tension face à la nécessité de préserver sa matrice identitaire, historiquement sédimentée. Et c'est exactement devant ce dilemme établi entre les facteurs d'ordre externe qui quotidiennement envahissent les écoles (administration centrale et périphérique, les communautés locales, entre autres) et les facteurs de nature interne à l'école (sociabilités, pratiques de convivialité, cérémonials, habitudes, traditions) que se jouent de nouvelles possibilités de repenser le développement démocratique des écoles. Dans cet article, nous avons repris l'idée d'école comme entrepôt culturel (Torres, 2004) - un espace de croisement de cultures, de métamorphoses quotidiennes de pouvoir et de conflit, de relations différenciées entre des acteurs scolaires et éducatifs —, avec l'intention de clarifier l'importance des dimensions culturelles et symboliques de l'organisation scolaire dans le développement de processus d'innovation et le changement et dans l'exploration (possibles) de liens d'assessorat éducative. Notre réflexion ne laissera pas, donc, d'interroger les temporalités et les logiques d'actions dans une présomption nouvelle espace scolaire, en interrogeant le rôle que les conséquents inputs culturels et politiques assument dans la construction de l'autonomie et de l'école démocratique.

Mots-clé

Culture scolaire; Culture organisationnelle d'école; Autonomie démocratique de l'école

Recebido em Março, 2007 Aceite para publicação em Novembro, 2007

Toda a correspondência relativa a este artigo deve ser enviada para: Leonor Lima Torres, Instituto de Educação e Psicologia, Universidade do Minho, Campus de Gualtar, 4710-057 Braga, Portugal. 